\title{
Particle Optimization of Ceo2/Water Nanofluids in Flat Plate Solar Collector
}

\author{
Shubham Sharma, Arun Kumar Tiwari, Sandeep Tiwari, Ravi Prakash
}

\begin{abstract}
The present research focuses on the role of $\mathrm{CeO}_{2} /$ water nanofluid for estimating the performance of flat plate solar collector in respect of energetic and exergetic performance. Based on our experimental findings on varying mass flow rate, the present analysis focuses on a wide range of concentrations to find optimum volume concentration for which thermal performance is maximum. $\mathrm{CeO}_{2}$ /water nanofluid exhibits high thermal conductivity improvement $(\sim 41.7 \%$ at $1.5 \%$ volume concentration) and comparatively lower dynamic viscosity. Performance evaluation of flat plate collector is based on first law analysis and qualitative nature of energy flow based on second law analysis. Experiments indicate that for $1.0 \%$ particle volume concentration at a mass flow rate of $0.03 \mathrm{~kg} / \mathrm{s}$, maximum collector efficiency is obtained up to $57.1 \%$ instead of water as the base fluid. Exergetic efficiency observed 84.6\%at optimum concentration ( $1.0 \%$ particle volume) of nanofluid at $0.01 \mathrm{~kg} / \mathrm{s}$ flow rate.
\end{abstract}

Keywords: Flat plate collector, Nanofluid, Exergy Efficiency, Energy efficiency, Optimization.

\section{INTRODUCTION}

Solar collectors with flat plate are most primitive type of collectors but these collectors are suffered from relatively low efficiency with the use of conventional fluids. To overcome this critical problem, an innovative type of fluid was invented by Choi [1] (1995) which is called "Nanofluid". Nowadays, most of the scientists and engineers are focusing on new nanotechnology and most efficient devices to harness the solar energy.Nanoparticles are the innovative materials with base fluids to enhance the heat absorbing transporting ability. Verma et al.[2]did research on solar collector of flat plate type for finding energetic and exergetic performance by using different oxide of nanoparticles in DM water. He had evaluated six different varieties of nanofluids having graphene, MWCNTs, $\mathrm{Al}_{2} \mathrm{O}_{3}$, $\mathrm{SiO}_{2}, \mathrm{TiO}_{2}$ and $\mathrm{CuO}$ as nanoparticles with base fluid water. Pandey et al.[3] reviewed on different methods to improve collector efficiency. They studied the various different numerical models and he found feasibility about the graphene/water nanofluid because of very high thermal conductivity and stability of fluid. Yousefiet al.

Revised Manuscript Received on December 30, 2019.

* Correspondence Author

Shubham Sharma*, Department of Mechanical Engineering, Amity University Uttar Pradesh, India. Email:Shubhamsharma1986@gmail.com

Arun Kumar Tiwari, Department of Mechanical Engineering, IET Lucknow India. Email: aruntiwari@ietlucknow.ac.in

Sandeep Tiwari, Director KEC, Ghaziabad, India. Email: sandeeptiwari1970@gmail.com

Ravi Prakash, Dean Faculty of Engineering \& Technology, Amity University Uttar Pradesh ,Noida, India. Email: rprakash@amity.edu

(C) The Authors. Published by Blue Eyes Intelligence Engineering and Sciences Publication (BEIESP). This is an open access article under the CC BY-NC-ND license (http://creativecommons.org/licenses/by-nc-nd/4.0/)
[4] had investigated the collector efficiency with or without the added surface active agent with $\mathrm{Al}_{2} \mathrm{O}_{3}$-water nanofluid experimentally and illustrated for $0.2 \mathrm{wt} \%$ of the nanofluid, efficiency increased up to $28.3 \%$ with respect to conventional fluids like water, ethylene glycol etc. Muhammad et al.[5] have reviewed about the usage of nanofluids to improve the thermal performance of collectors. He had studied about the recent research work on FPC, ETC and DAC related to enhancement in performance of all three collectors and suggested about the hybrid type of nanofluids (two nanoparticles + base fluid) for heat transfer enhancement in FPSC.

Tiwari et al.[6] reviewed the usage of nanoparticles in collectors. He represents about the progressive evaluation on the analysis of applications of nanoparticles with base fluids for enhancing the instant collector efficiency and give more attention on thermal properties, optical properties, magnetic properties, electrical properties, convective heat transfer coefficient. Javadiet al.[7]did research on solar collectors for identifying the performance by using nanofluids. Study reveals that in direct absorption solar collector there is tremendous change in optical properties by using nanoparticles. Authors suggested future research workto minimize uncertainties in nanofluids by doing study in 2phase manner.Sharafeldinet al.[8]did study on flat plate solar collector for finding the performance by using $\mathrm{WO}_{3} /$ Water nanofluid. Suman et al.[9]has reviewed comprehensively methodologies used to examined the collector performance. He reported that improvement in various solar collectors can be enhanced by applying collector coating, geometrical modifications and stability of nanoparticles in ethylene glycol.

Tiwari et al.[10]concentrated on the role of nanofluids in thermal properties (thermal conductivity, viscosity, density, specific heat, particle size) and for the most part on volume division dependent on exploratory observations. Authors suggest that more potential research is still awaited to get the long-term stability for incredible performance enhancement.Said et al.[11] has experimentally investigated the energy and exergy analysis by using $\mathrm{Al}_{2} \mathrm{O}_{3}$ nanofluid having different size of nanoparticles diameter, the two different sizes $13 \mathrm{~nm}$ and $20 \mathrm{~nm}$ of $\mathrm{Al}_{2} \mathrm{O}_{3}$ nanoparticles were used and found that thermal conductivity enhancement and efficiency was highest for $13 \mathrm{~nm} \mathrm{Al}_{2} \mathrm{O}_{3}$ nanoparticle, compared to that of $20 \mathrm{~nm} \quad \mathrm{Al}_{2} \mathrm{O}_{3}$ nanoparticle. Shojaeizadehet al.[12]did investigation on $\mathrm{Al}_{2} \mathrm{O}_{3} /$ Water nanofluid for improving the performance of collector and solar radiation, result reveals $0.72 \%$ exergy efficiency. Sharafeldinet al.[13] had carried out the researchwith dispersing the cerium oxide nanoparticles in base fluid like water experimentally. Kasaeianet al.[14]study the solar energy system by using nanofluids. 


\section{Particle Optimization of Ceo2/Water Nanofluids in Flat Plate Solar Collector}

This research illustrated solar thermal electronics, photovoltaic and different variety of solar collectors. Verma et al.[15]did research on collector for finding the efficiency at different flow rates of nanofluids. Result shows $31.64 \%$ of collector efficiency was observed by using $\mathrm{Al}_{2} \mathrm{O}_{3} /$ Water nanofluid with $1.5 \%$ volume concentration.Sarsamet al.[16] carried some reviews on FPSC at different oxides of nanoparticles.

Previous experimental and theoretical investigations are covered in this review paper and concluded that application of nanofluids effectively enhance the thermophysical properties and efficiency of flat plate collectors and authors also suggest that further research is needed with high thermal conductivity in some newly-developed nanoparticles.Nagarajan et al.[17] reviewed the nanofluids for solar collectors applications. A comprehensive study has been carried out on the application of solar collector with nanofluids and thermophysical properties of nanofluids have compiled. Zamzamianet al.[18]did research on synthesized $\mathrm{Cu} / \mathrm{EG}$ nanofluid by using volume concentration $(0.1 \%$, $0.2 \%$, and $0.3 \%$ ) for finding thermal properties at varying temperatures. Dharmalingamet al.[19]studied an about the effect of various nanomaterials at different particle volume concentrations because of inherent thermal characteristics of nanofluids. This paper summarized about latest research work, development of enhancing heat transfer by using nanofluids, analyzing the challenges and their physical and chemical properties. Gencet al. [20]did experimental research on solar collector for finding thermal performance by using $\mathrm{Al}_{2} \mathrm{O}_{3} /$ Water nanofluid, result found $74.39 \%$ of maximum collector efficiency with $3 \%$ volume concentration in the month of July. Jouybariet al.[21]study the effect of different types of nanoparticles and various porous channels in the field of FPSC. He reported that the thermal conductivity has a considerable improvement in thermal performance using $\mathrm{SiO}_{2}$ /deionized water nanofluids in FPSC as compare to other conventional nanofluids. Sharmaet al.[22] reviewed about the rheological behavior in nanofluids and reported that the nanofluids which exhibit Newtonian behavior for spherical nanoparticles have a very low value of shear rate. Vermaet al.[23-24]studied the hybrid nanofluid in collectors for finding thermal characteristics. They found that $71.54 \%$ and $70.55 \%$ of exergetic and energetic efficiency by using hybrid $\mathrm{MgO}$ nanofluid and $70.63 \%$ and $69.11 \%$ by using hybrid $\mathrm{CuO}$ nanofluid. They concluded that the MgO hybrid nano fluids were more efficient than $\mathrm{CuO}$ hybrid nanofluids and more closure to MWCNTs-water fluid. The review of literature shows there is a need for more comprehensive analysis of a wide range of nanofluids, their concentrations and particle sizes.

The present work is concerned with an impact analysis of a wide spectrum of $\mathrm{CeO}_{2}$ /water nanofluids on energetic and exergetic performance of flat plate solar collectors. Analysis of energetic performance has focused on qualitative behavior of solar collector in converting solar energy into other forms for performing useful functions. Exergy analysis has also provided useful statisticson optimum design of solar thermal systems and choice of nanofluids with optimum concentration. A wide range of concentrationsof $\mathrm{CeO}_{2}$ /water nanofluidhave been examined to find optimum vol. concentration for which thermal performance is maximum.

\section{EXPERIMENTAL CONSIDERATION}

\section{A. Synthesis and measurement of thermophysical properties}

In this present work, the synthesis of nanofluid which is used for experimentation and determination of thermophysical property is presented.Synthesis of $\mathrm{CeO}_{2}$ /water nanofluid is done by mixing of nanofluid in a beaker filled with double distilled water. Two step methods is most effective method for preparation of nanofluid and samples has been prepared for experimentation of flat plate collector and characterization of nanofluid.In this method, $\mathrm{CeO}_{2}$-water nanoparticles with $30 \mathrm{~nm}$ particle size are dispersed into the base fluid in the form of powder. A mechanical mixer is used for proper mixing of nanoparticles into the base fluid for one hour and then this solution is dispersed into the De-mineralized water as base fluid using Homogenizer for about 4 to 5 hours. Ultra-Sonicator is used for mixed the nanofluid properly to avoid agglomeration and sedimentation in solution. The samples of required volume concentration are prepared in the following: $0.25 \%, 0.50 \%$, $0.75 \%, 1.0 \%, 1.25 \%$ and $1.50 \%$ and homogeneoussolution are obtained continuously for 6-8 h using ultrasonic vibrator. To break down the agglomerated particles and dispersed the nanoparticles properly in solution, a magnetic stirrer is used. To get the long-term stability, a surfactant (Triton X-100) is added in a very small quantity by the supplier who manufactures the nanofluidwithout adversely affecting basic characteristics of nanoparticles.To attain proper stability of nanoparticles in base fluid, repetition of mechanical mixing and ultrasonic sonification is done at the time of performing test of each sample.

The measurement of nanofluid thermal conductivity was done by using transient hot-wire apparatus (KD-2 Thermal Properties Analyzer, Decagon Devices, Inc., USA). Similarly, viscosity measurement is done by using LVDVII+ProBrookfieldviscometer (cone and plate, SpindleCPE42).

\section{B. Data Interpretation}

The helpful heat energy rate can likewise be communicated in terms of the distinction between solar radiation energy absorbed by solar collector and the energy lost from the collector absorber plate as given by Eq. (1).

$$
\mathrm{Qu}_{\mathrm{u}}=\mathrm{A}_{\mathrm{c}} \mathrm{F}_{\mathrm{R}}\left[\mathrm{I}_{\mathrm{t}}\left(\tau_{0} \alpha_{0}\right)-\mathrm{U}_{\mathrm{L}}\left(\mathrm{T}_{\mathrm{i}}-\mathrm{T}_{\mathrm{a}}\right)\right]
$$

Where $A_{c}$ is the collector gross area, $\mathrm{F}_{\mathrm{R}}$ is the collector heat removal factor, $I_{t}$ is the intensity of solar radiation normal to the collector, $\tau_{0}$ and $\alpha_{0}$ is transmittance and absorptance, $\mathrm{T}_{\mathrm{a}}$ is the ambient temperature and $\mathrm{U}_{\mathrm{L}}$ is the overall heat loss coefficient.

Now, heat removal factor, $F_{R}$ can be calculated by the following expression used in Eq. (2).

$$
\begin{aligned}
& \mathrm{F}_{\mathrm{R}} \\
& =\frac{\mathrm{mC}_{\mathrm{p}}\left(\mathrm{T}_{\mathrm{o}}-\mathrm{T}_{\mathrm{i}}\right)}{\mathrm{A}_{\mathrm{c}}\left[\mathrm{I}_{\mathrm{t}}\left(\tau_{\mathrm{o}} \alpha_{\mathrm{o}}\right)-\mathrm{U}_{\mathrm{L}}\left(\mathrm{T}_{\mathrm{i}}-\mathrm{T}_{\mathrm{a}}\right)\right]}
\end{aligned}
$$

Another formula for heat extraction factor $\left(F_{R}\right)$, 
$F_{R}=\frac{\dot{m} c_{p}}{A_{c}}\left[1-\exp \left(-\frac{U_{L} F^{\prime} A_{C}}{\dot{m} c_{p}}\right)\right]$

Here, $F^{\prime}$ is the collector efficiency factor.

The thermal efficiency of flat plate solar collector is explained as ratio of the useful power extracted from the collector to the input energy coming from the solar radiations received by the absorber plate of the solar flat plate collector.

Collector efficiency can be calculated with the use of Eq. (4). In addition, experiments must be done under steady state conditions.

$$
\eta_{\mathrm{c}}=\frac{\mathrm{Q}_{\mathrm{u}}}{\mathrm{A}_{\mathrm{c}} \mathrm{I}_{\mathrm{t}}}(4)
$$

Where $\eta_{i}$ is the instantaneous efficiency of flat plate solar collector or simply says collector efficiency.

Further, the instantaneous efficiency can be described by Eq. (5) or (6) as follows:

$$
\begin{aligned}
& \eta_{\mathrm{c}}=\frac{\rho V \mathrm{C}_{\mathrm{p}}\left(\mathrm{T}_{\mathrm{o}}-\mathrm{T}_{\mathrm{i}}\right)}{\mathrm{A}_{\mathrm{c}} \mathrm{I}_{\mathrm{t}}}(5) \\
& \eta_{\mathrm{c}}=\frac{\mathrm{A}_{\mathrm{c} \mathrm{F}_{\mathrm{R}}\left[\mathrm{I}_{t}\left(\tau_{o} \alpha_{o}\right)-\mathrm{U}_{\mathrm{L}}\left(\mathrm{T}_{\mathrm{i}}-\mathrm{T}_{\mathrm{a}}\right)\right]}^{\mathrm{A}_{\mathrm{c}} \mathrm{I}_{\mathrm{t}}}(6)}{\eta_{\mathrm{c}}}=\mathrm{F}_{\mathrm{R}}\left(\tau_{o} \alpha_{o}\right)- \\
& \mathrm{F}_{\mathrm{R}} \mathrm{U}_{\mathrm{L}}\left(\frac{\mathrm{T}_{\mathrm{i}}-\mathrm{T}_{\mathrm{a}}}{\mathrm{I}_{\mathrm{t}}}\right)
\end{aligned}
$$

First law of thermodynamics (energy analysis): Thermal energy balance equation

$$
\begin{aligned}
& m_{p} C_{p}\left(d T_{P, \text { wov }} / d t\right)+\dot{m}_{C_{p}}\left(T_{\text {out }}-T_{\text {in }}\right)=\eta_{o} I A_{c}-U_{C}\left(T_{P, \text { wrg }}-T_{e}\right) T_{C}(8) \\
& \dot{E}_{x, \text { heat }}-\dot{E}_{x, \text { work }}-\dot{E}_{x, \text { mass,in }}-\dot{E}_{x, \text { mass,out }}=\dot{E}_{x, \text { dest }}(9)
\end{aligned}
$$

Substituting terms into this equation yields:

$$
\begin{aligned}
& \sum\left(1-\frac{T_{a}}{T_{\text {Sur }}}\right) \dot{Q}_{S}-\dot{W}+\sum \dot{m}_{\text {in }} \psi_{\text {in }}-\sum \dot{m}_{\text {out }} \psi_{\text {out }}=\dot{E}_{x, \text { dest }} \\
& \sum\left(1-\frac{T_{a}}{T_{\text {sur }}}\right) \dot{Q}_{S}-\dot{m}\left(h_{\text {out }}-h_{i n}\right)-T_{a}\left(S_{\text {out }}-S_{\text {Sin }}\right)=\dot{E}_{\text {xdest }}(11)
\end{aligned}
$$

Where $\dot{Q}_{s}$ is the total rate of exergy received from the solar radiation by the collector absorbed area.

$$
\dot{Q}_{S}=I_{t}(\tau \alpha)=S A_{c}
$$

The change in enthalpy and entropy of the nanofluid in the collector is:

$$
\begin{aligned}
& \Delta h=h_{\text {out }}-h_{\text {in }}=c_{p, n f}\left(T_{f}, \text { out }-T_{f} \text {,in }\right)(13) \\
& \Delta S=S_{\text {out }}-S_{\text {in }}=C_{p, n f} \ln \frac{T_{f}, \text { out }}{T_{f, \text { in }}}-R \ln \frac{p_{\text {out }}}{p_{\text {in }}}
\end{aligned}
$$

Where $\dot{E}_{x d e s t}$ is the exergy loss or irreversibility rate defined as:

$$
\begin{aligned}
& \dot{E}_{x d e s t}=T_{a} \cdot S_{\text {gen }} \\
& \eta_{e x}=1-\frac{T_{a} S_{g e n}}{\left[1-\frac{T_{a}}{T_{s}}\right] Q_{s}}
\end{aligned}
$$

Pumping power and pressure drop:

$$
\Delta n_{e x}=\frac{\Delta \dot{I}}{\dot{E}_{\text {x heat }}}+\frac{\dot{I}_{\dot{E}_{\text {xheat }}}}{\dot{E}_{x^{2} \text { heat }}} \quad \Delta p=f \frac{\rho V^{2}}{2} \frac{\Delta l}{d}+k \frac{\rho V^{2}}{2}
$$

$$
\Delta \eta_{g e n}=\frac{\Delta \dot{q}_{a}}{G_{C}}+\frac{\dot{q}_{a} \Delta G_{C}}{G_{C}^{2}}
$$

Where each error component can be analyzed through the following relations:

$$
\begin{gathered}
\Delta E_{\text {xheat }}=\left(\frac{\Delta T}{T_{s}}+\frac{T_{a} \Delta T}{T_{s}^{2}}\right) A_{C}(\tau \alpha) G_{C}+\left(1-\frac{T_{a}}{T_{s}}\right) A_{C}(\tau \alpha) \Delta G_{C} \\
\Delta \dot{\boldsymbol{I}}=\mathbf{T}_{\boldsymbol{a}} \Delta \dot{\boldsymbol{S}}_{\text {gen }}+\dot{\boldsymbol{S}}_{\text {gen }} \Delta \boldsymbol{T}
\end{gathered}
$$

\section{EXPERIMENTAL SETUP}

The setup for experiment consists of a flat plate collector, which is capable for trapping the intensity of incident radiation in the form of heat by absorber plate mounted on the surface of the solar collector. Human interaction machine, achiller for heating and cooling nanofluid, rotameters regulate the mass flux rates about $5 \mathrm{l} / \mathrm{min}$. Flow direction is adjusted with the use of athree-way solenoid valve, two pumps $(500 \mathrm{~W})$ are used for circulating the flow and pressure is measured by a pressure indicator for both DM water and nanofluid.Table 1 shows the technical specifications of FPSC. The photograph of the experimental setup is shown in Fig. 1.

\section{EXPERIMENTAL PROCEDURE}

Apparatus consist of the solar module with $500 \mathrm{~W}$ capacity of 8 halogen lights having an adjustable inclination. The radiation intensity has been varied with increasing the power of halogen lights with a knob.The maximum intensity of this system is observed up to $\sim 1300 \mathrm{~W} / \mathrm{m}^{2}$ (avg.). Before circulating the nanofluid and DM water as the base fluid in the circuit, set temperature of both DM water and nanofluid should be maintained properly by using chiller and heater devices. Circulation of both DM water and nanofluid should be one time. For storage of nanofluid and DM water, two insulated steel tanks are preferredwith the separate circuit having $10 \mathrm{~L}$ capacity. For circulation of nanofluid and DM water, two separate pumps of $500 \mathrm{~W}$ are required because of force mode of experimental setup. Pressure indicators are used to measure the loss of pressure in $\mathrm{kP}_{\mathrm{a}}$ between both inlet and outlet. Three-way by pass valves are used for testing of DM water and nanofluid. Rotameters are used tomeasure flow discharge with a range from 0 to $5 \mathrm{lpm}$ and least count $0.1 \mathrm{lpm}$. 


\section{Particle Optimization of Ceo2/Water Nanofluids in Flat Plate Solar Collector}

Solar irradiations are measured by a precise instrument i.e.Solarimeter (TENMARS-TM-207) which is capable to measure solar intensity from 0 to $2200 \mathrm{~W} / \mathrm{m}^{2}$. To measure the inlet or set temperature and outlet temperature (T-2 and T-1), K-type thermocouples are used as shown in the schematic. 6 K-type thermocouples are used to measure plate temperature and these thermocouples are attached with the surface of the absorber plate. Modeler is attached with the maximum capacity of $4 \mathrm{~kW}$ at a temperature of $\sim 3000 \mathrm{~K}$ in the plate of a solar collector. The intensity of solar radiation is not steady in the whole universe, so modeler is required for steady state solar radiation where the thermal efficiency can be observed maximum compared to the actual source of solar energy. This is the complete working of the experimental setup.

Table- I:Technical specifications of flat plate collector

\begin{tabular}{|l|c|c|}
\hline Specification & Dimension & Unit \\
\hline Absorption area & 0.375 & $\mathrm{~m}^{2}$ \\
\hline Back insulation thickness & 5 & $\mathrm{~cm}$ \\
\hline Collector occupied area & $\begin{array}{l}75 \times 50 \\
\times 6.3\end{array}$ & $\mathrm{~cm}$ \\
\hline Collector riser tube outer dia $\left(\mathrm{D}_{\mathrm{o}}\right)$ & 1 & $\mathrm{~cm}$ \\
\hline Collector riser tube inner dia $\left(\mathrm{D}_{\mathrm{i}}\right)$ & 0.8 & $\mathrm{~cm}$ \\
\hline Center distance between tubes & 3 & $\mathrm{~cm}$ \\
\hline Conductivity of back insulation & 0.04 & $\mathrm{~W} / \mathrm{m} \mathrm{K}$ \\
\hline Edge area of collector & 0.1572 & $\mathrm{~m}^{2}$ \\
\hline Emissivity of absorbing & 0.12 & dimensionless \\
\hline $\begin{array}{c}\text { Effective absorptivity } \\
\text { transmitivity product }\end{array}$ & 0.816 & dimensionless \\
\hline Emissivity of glass cover & 0.88 & dimensionless \\
\hline Glazing thickness & 4 & $\mathrm{~mm}$ \\
\hline Number of glazing plate & $76 \times 51$ & 1 \\
\hline $\begin{array}{l}\text { Thermal conductivity of absorbing } \\
\text { plate }\end{array}$ & 390 & $\mathrm{~W} / \mathrm{m} \mathrm{K}$ \\
\hline Weight of collector & 15 & $\mathrm{~kg}$ \\
\hline
\end{tabular}

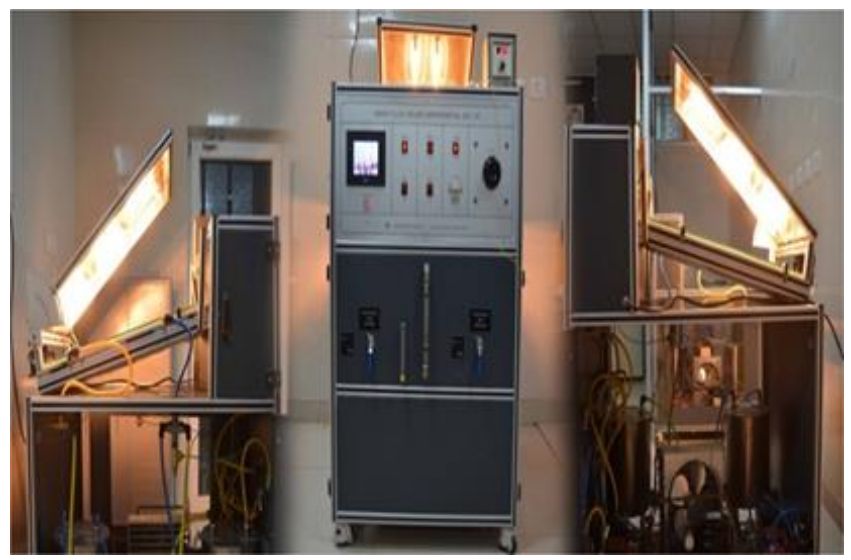

Fig. 1. Photograph of the experimental setup

\section{UNCERTAINTY ANALYSIS}

At the time of performing experimental work in the laboratory, some uncertainties have arisen which are pointed out in Table 2. Uncertainty analysis is required to calibrate the equipments for accurate measurements in experimental work for determination of collector efficiency. Uncertainty depends on the specific heat, collector area, solar irradiation, mass flux rates and inlet and outlet temperature of working fluid.

Table- II: Uncertainties during measurement of experimental parameters

\begin{tabular}{|l|l|}
\hline Variable & $\begin{array}{l}\text { Uncertainty value } \\
(\%)\end{array}$ \\
\hline
\end{tabular}

\begin{tabular}{|c|c|}
\hline Nanofluid inlet temperature & \pm 0.15 \\
\hline Nanofluid outlet temperature & \pm 0.15 \\
\hline Hot inlet temperature & \pm 0.15 \\
\hline Hot outlet temperature & \pm 0.15 \\
\hline Nanofluid side mass flux rate & \pm 2.4 \\
\hline Hot side mass flux rate & \pm 2.4 \\
\hline $\begin{array}{l}\text { Nanofluid side } \\
\text { pressure }\end{array}$ & \pm 2.2 \\
\hline Hot side differential pressure & \pm 2.2 \\
\hline $\begin{array}{l}\text { Nanofluid thermal conductivity } \\
\text { measurements }\end{array}$ & \pm 4.5 \\
\hline $\begin{array}{ll}\text { Nanofluid } & \text { viscosity } \\
\text { measurements } & \end{array}$ & \pm 3.5 \\
\hline $\begin{array}{ll}\text { Nanofluid } & \text { density } \\
\text { measurements } & \end{array}$ & \pm 4.0 \\
\hline $\begin{array}{l}\text { Nanofluid specific heat } \\
\text { measurements }\end{array}$ & \pm 4.5 \\
\hline
\end{tabular}

\section{RESULTS AND DISCUSSIONS}

Experimental results are indicated that the thermal conductivity increases linearly at different volume concentration and varying temperatures as shown in Fig. 2.Thermal conductivity mainly depends on the temperatures because of the energized nanoparticles with the molecules of the base fluid. It can be concluded that the nanofluids have lot of potential as compare to base fluids to enhance the heat transportability. Variation in performance parameters to enhance thermal conductivity is followed as: type of base fluid, particle volume fraction, $\mathrm{pH}$ value, temperature, the shape of a nanoparticle, type of material, surfactant and size of nanoparticles. From experimental data, thermal conductivity is observed for $55^{\circ} \mathrm{C}$ are 0.634 for $\mathrm{DM}$ water and $0.781,0.786,0.798,0.807,0.815,0.825 \mathrm{~W} / \mathrm{m} \mathrm{K}$ for volume concentration at $0.25 \%, 0.50 \%, 0.75 \%, 1.0 \%, 1.25 \%$ and $1.5 \%$. Similarly for $60^{\circ} \mathrm{C}$, thermal conductivity for DM water is 0.638 and $0.799,0.806,0.815,0.822,0.831,0.842$ $\mathrm{W} / \mathrm{m} \mathrm{K}$ for same volume concentration and for $65^{\circ} \mathrm{C}$, thermal conductivity for DM water is 0.643 and 0.811 , $0.821,0.830,0.839,0.848,0.861 \mathrm{~W} / \mathrm{m} \mathrm{K}$ for same volume concentration and for $70^{\circ} \mathrm{C}$, thermal conductivity for $\mathrm{DM}$ water is 0.648 and $0.834,0.840,0.848,0.856,0.865,0.883$ $\mathrm{W} / \mathrm{m} \mathrm{K}$ for same volume fraction and for $75^{\circ} \mathrm{C}$, thermal conductivity for DM water is 0.653 and $0.849,0.861,0.868$, $0.878,0.887,0.909 \mathrm{~W} / \mathrm{m} \mathrm{K}$ for same volume concentration and for $80^{\circ} \mathrm{C}$, thermal conductivity for $\mathrm{DM}$ water is 0.659 and $0.865,0.883,0.892,0.901,0.910,0.934 \mathrm{~W} / \mathrm{m} \mathrm{K}$ for same volume concentration respectively. 


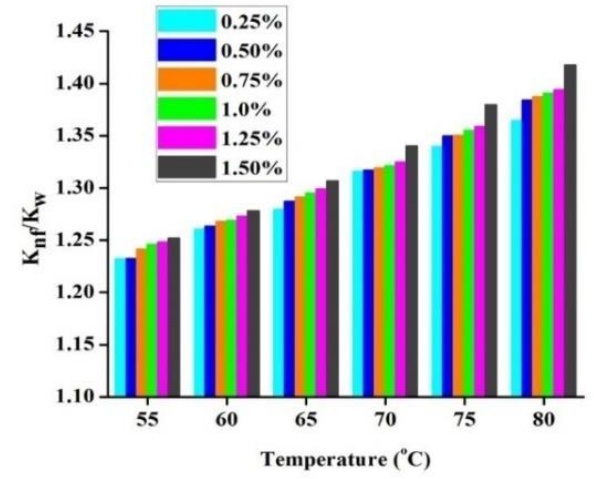

Fig. 2. Graph between $K_{n f} / K_{w}$ and temperature

Viscosity is an inherent thermophysical property of fluids which arises due to frictional resistance between the adjacent layer of nanoparticles and fluids. It has the ability to transport heat of energy systems to improve the performance of the nanofluids. The viscosity of the used nanofluid is measured using the LVDV-II + Pro Brookfield Digital Viscometer Brookfield Engineering Laboratories, Inc.). The repeatability and accuracy are $\pm 1.0 \%$ and $\pm 0.2 \%$ respectively of the viscometer which is indicated by the manufacturer. The calibration of the viscometer is done with the DM water before the measurements and maximum uncertainty is computed lower than $0.2 \%$ in the measurement of viscosity. To set the temperatures of used nanofluid at different degrees, a computer controlled temperature bath is used for accurate measurement of viscosity. Pressure drop and fractional loss can be determined correctly due to variation in viscosity by experimental observation. Viscosity of the used nanofluid is measured at varying temperatures $\left(55^{\circ} \mathrm{C}, 60^{\circ} \mathrm{C}, 65^{\circ} \mathrm{C}, 70^{\circ} \mathrm{C}\right.$, $75^{\circ} \mathrm{C}$ and $80^{\circ} \mathrm{C}$ ) and volume concentration $(0.25 \%, 0.50 \%$, $0.75 \%, 1.0 \%, 1.25 \%$ and $1.50 \%$ ) respectively.From the observation of experimental data, it is concluded that the viscosity increases linearly with particle volume fraction due to cohesive forces among like and unlike molecules increases at higher particle volume concentration as shown in Fig. 3 for $\mathrm{CeO}_{2}$ /water based nanofluid respectively. Further viscosity decreases with an increase in temperature because of fall in cohesive forces predominantly and across the adjacent layers, the viscosity increases marginally due to enhanced momentum transfer. Viscosity is more expressive in liquids due to cohesive forces than due to momentum transfer across the adjacent layers of the fluids.

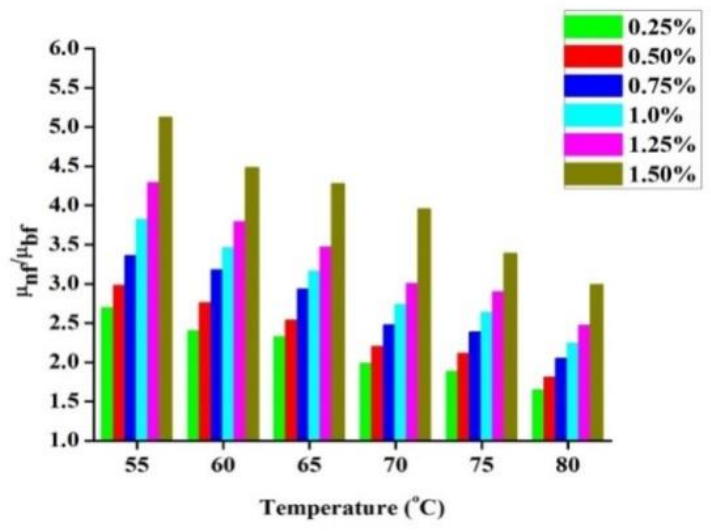

Fig. 3. Graph between ratio of viscosity versus temperature
Experimental observation of flat plate collector is administrated to find out variation in collector efficiency at varying mass flow rates $(0.01 \mathrm{~kg} / \mathrm{s}, 0.02 \mathrm{~kg} / \mathrm{s}, 0.03 \mathrm{~kg} / \mathrm{s}, 0.04$ $\mathrm{kg} / \mathrm{s}$ and $0.05 \mathrm{~kg} / \mathrm{s}$ ) and at different particle volume concentration $(0.25 \%, 0.50 \%, 0.75 \%, 1.0 \%, 1.25 \%, 1.50 \%$ and $2.0 \%$ ). Fig. 4 and 5 show the relation between collector efficiency and particle concentration at varying mass flow rates. In this graph, collector efficiency increases for each mass flow rate of nanofluid with volume concentration up to a certain point of volume concentration (1\%) and decreases the collector efficiency with particle concentration after this valuable point of concentration. Experimental results exhibit that the maximum efficiency of flat plate collector is observed $57.1 \%$ at optimum particle concentration (vol 1\%) with $0.03 \mathrm{~kg} / \mathrm{s}$ mass flow raterespectively.

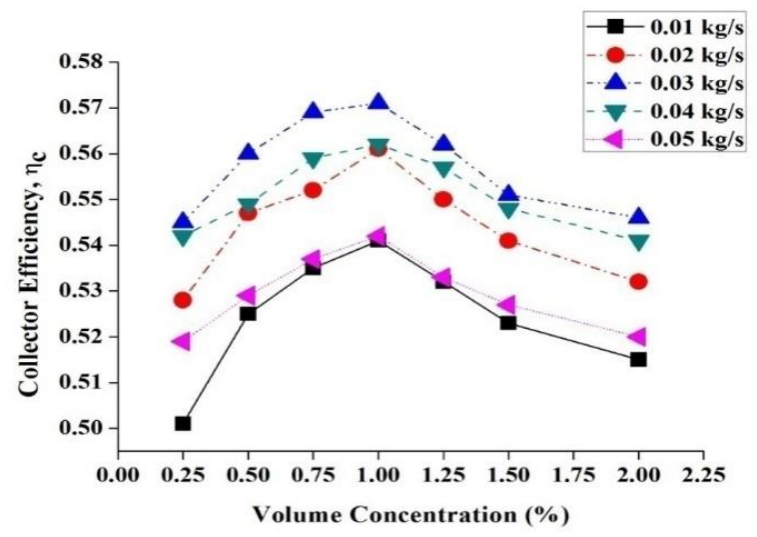

Fig. 4. Collector efficiency versus Volume fraction

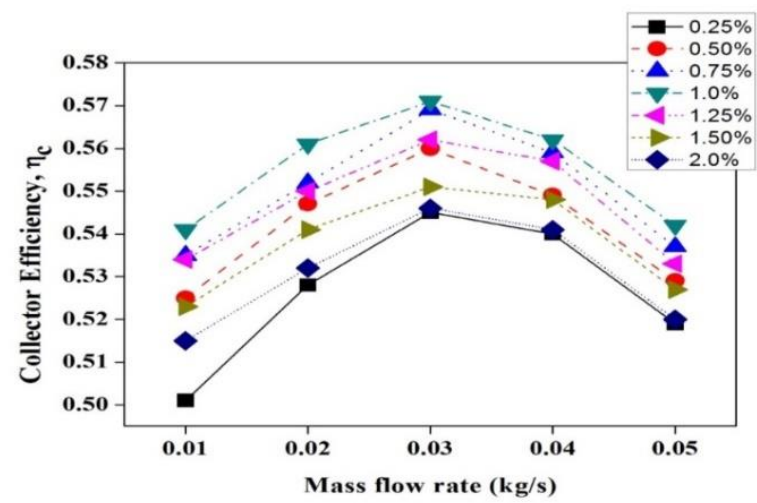

Fig. 5. Collector efficiency versus mass flow rate

Figure 6 illustrates the collector efficiency and reduced temperature difference parameter at the volume concentration of $0.25 \%$ to $2 \%$. From the observed data, the efficiency of flat plate collector is inversely proportional to temperature reduced parameter at different particle concentrations. It means collector efficiency increases with decreasing the temperature reduced parameter. Experimental results shows that the maximum efficiency is observed $65.3 \%$ at optimum particle concentration (vol 1\%) with temperature reduced parameter of $0.005 \mathrm{~m}^{2} \mathrm{~K} / \mathrm{W}$ and minimum collector efficiency is measured $54.6 \%$ at temperature reduced parameter of $0.02 \mathrm{~m}^{2} \mathrm{~K} / \mathrm{W}$ with particle volume fraction of $2 \%$ respectively. So, the temperature reduced parameter should be minimum for enhancement in efficiency of flat plate collector.

The intensity of radiation is the heart of any kind of 


\section{Particle Optimization of Ceo2/Water Nanofluids in Flat Plate Solar Collector}

collector because collector efficiency depends on solar intensity at varying particle concentrations from $0.25 \%$ to $2 \%$. Results illustrate that the maximum collector efficiency is obtained $58.1 \%$ at an optimum particle concentration (vol $1 \%$ ) with solar intensity of $700 \mathrm{~W} / \mathrm{m}^{2}$ and minimum collector efficiency is observed $43.1 \%$ at the intensity of 300 $\mathrm{W} / \mathrm{m}^{2}$ with concentration of $2 \%$ respectively. From experimental data, collector efficiency decreases beyond optimal values as shown in Figure 7.

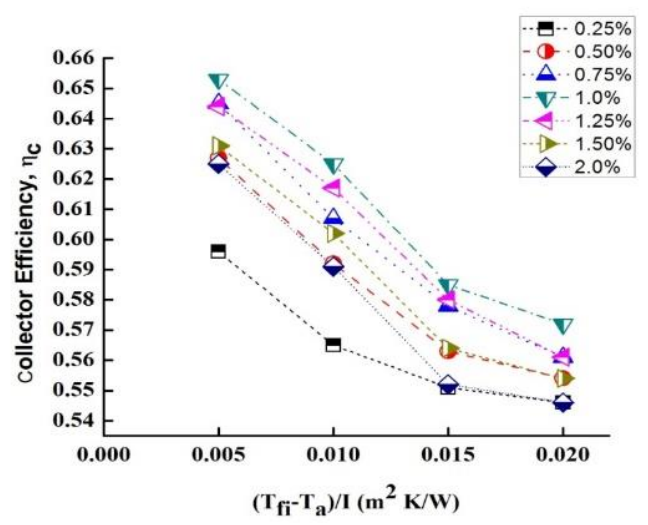

Fig. 6. Collector efficiency versus reduced temperature difference parameter

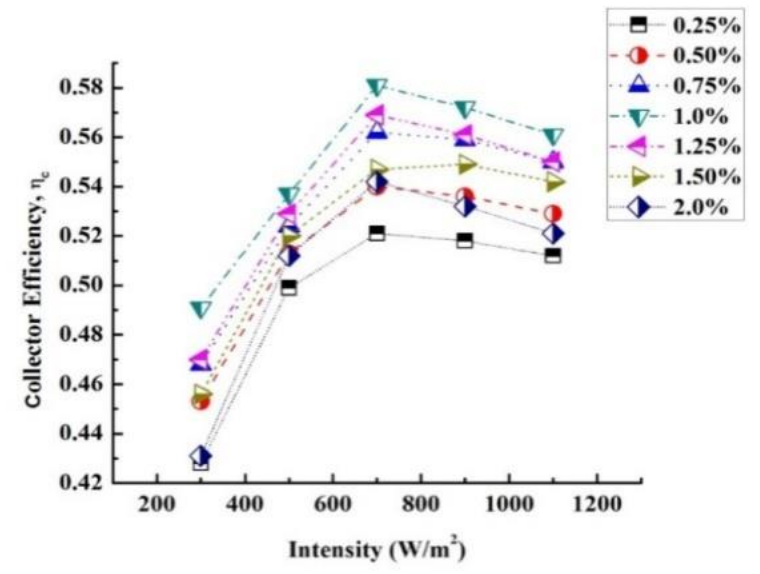

Fig. 7.Graph between collector efficiency and radiation intensity

Entropy generation is the drawback for enhancement in collector performance which encourage to move in the field of nanotechnology.Entropy generation is determined from experimental data and plotted the graph as shown in Fig. 8at varying the mass flow rates $(0.01 \mathrm{~kg} / \mathrm{s}, 0.02 \mathrm{~kg} / \mathrm{s}, 0.03 \mathrm{~kg} / \mathrm{s}$, $0.04 \mathrm{~kg} / \mathrm{s}$ and $0.05 \mathrm{~kg} / \mathrm{s}$ ) and at different particle volume concentration $(0.25 \%, 0.50 \%, 0.75 \%, 1.0 \%, 1.25 \%, 1.50 \%$ and $2.0 \%$ ). From the measured values, the entropy generation for DM water is found to be maximum 0.374 $\mathrm{W} / \mathrm{K}$ at a mass flow rate of $0.05 \mathrm{~kg} / \mathrm{s}$. Entropy generation for all the particle volume concentration of $\mathrm{CeO}_{2}$-water nanofluid is minimum in comparison with base fluid. Results shows that the minimum entropy generation is determined $0.03 \mathrm{~W} / \mathrm{K}$ at optimum particle concentration (vol $1 \%$ ) with mass flow rate of $0.01 \mathrm{~kg} / \mathrm{s}$.

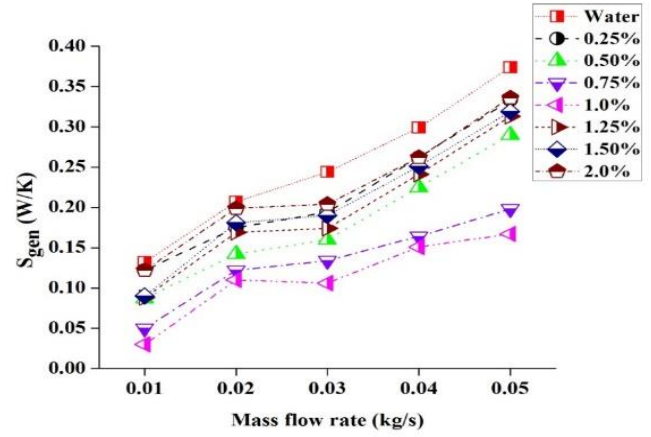

Fig. 8. Entropy generation versus mass flow rate

The graph between exergetic efficiency and mass flow rate is presented in Fig. 9 and illustrates that the exergetic efficiency increases with decreasing the mass flow rate of DM water and nanofluid at all volume concentrations. Exergetic efficiency is defined as whatever radiation incident on the flat plate solar collector that irradiations absorbed by the absorber plate and absorber plate converts these irradiations in the form of heat energy. This heat energy goes into the copper tubes which contains fluids in the form of liquids. There are several losses i.e. top losses, bottom losses, edge losses etc. occurred in the whole process. Apart from these losses, whatever energy is available that heat energy is useful energy and this useful energy is known as exergetic energy and this exergetic energy is required to determine true exergetic efficiency.

From the measurement of experimental data, it is observed that the maximum exergetic efficiency is obtained $84.6 \%$ at optimum particle concentration (vol 1.0\%) with decreasing the rate of mass flow $(0.01 \mathrm{~kg} / \mathrm{s})$ and minimum exergetic efficiency is calculated $24.2 \%$ at $0.05 \mathrm{~kg} / \mathrm{smass}$ flow rate of base fluid. Results exhibits that the exergy efficiency increases with decreasing the mass flow rates of DM water and nanofluid but exergy efficiency is found higher for each particle volume concentration of $\mathrm{CeO}_{2}$-water nanofluid in comparison with base fluid. From observing all the experimental results, it exhibits that the nanofluids have superior thermal properties to enhance the performance of the flat plate solar collector.

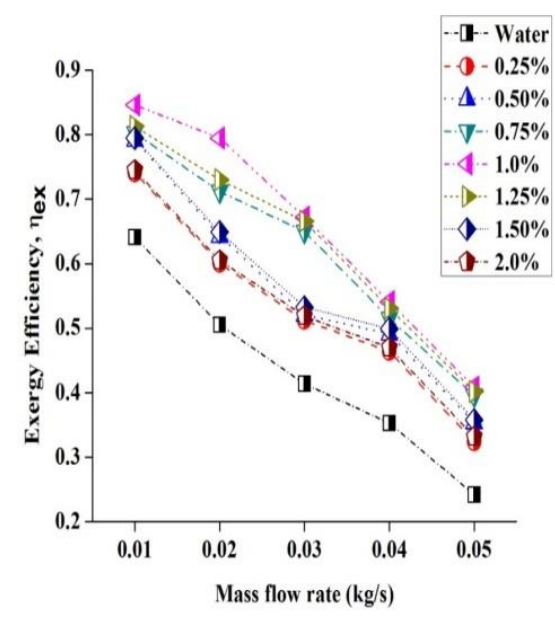

Fig. 9. Graph between exergetic efficiency and mass flow rate 


\section{CONCLUSIONS}

In present work, the impact of mass flow rate and particle volume fraction on the thermal performance of the flat plate collector is experimentally observed. The systematic measurement of all the related thermophysical properties (density, specific heat, viscosity and thermal conductivity) involved in heat exchanging processes are measured experimentally for $\mathrm{CeO}_{2}$ /water nanofluids at different particle volume concentration $(0.25 \% \sim 2.0 \%)$ and at different temperatures $\left(55^{\circ} \mathrm{C} \sim 80^{\circ} \mathrm{C}\right)$. On the basis of various experiment, it has been found that $1.0 \%$ volume concentration is optimum for different operating conditions. The finding reveals that a use of $\mathrm{CeO}_{2} /$ water at optimum particle volume concentration and $0.03 \mathrm{~kg} / \mathrm{s}$ mass flow rate, maximum collector efficiency has been calculated 57.1\%.At $0.005 \mathrm{~m}^{2} \mathrm{~K} / \mathrm{W}$ temperature reduced parameter and optimum volume fraction, efficiency is observed $65.3 \%$ and for 700 $\mathrm{W} / \mathrm{m}^{2}$ intensity of radiation, maximum instantaneous efficiency is found $58.1 \%$ at optimum concentration. Exergy efficiency is vital parameter to improve the thermal performance of flat plate collector. For $0.01 \mathrm{~kg} / \mathrm{s}$ mass flow rate and optimum concentration (vol 1.0\%), exergetic efficiency is obtained $84.6 \%$.Highest entropy generation has observed $0.374 \mathrm{~W} / \mathrm{K}$ at $0.05 \mathrm{~kg} / \mathrm{s}$ mass flow rate with the use of base fluid which is the major drawback for improvement in performance of flat plate solar collector.

\section{FUTURERECOMMENDATIONS}

- Long-term stability of nanofluids suspension is still needed more attention.

- Hybrid nanofluids will be the new challenging area for researchers and scientists.

- Research should be carried out on the effect of particle shape on thermal performance of solar system.

- Practical applications of usage of nanofluid are still in critical phase due to the formation of sedimentation, agglomeration and clogging in a flow path.

\section{REFERENCES}

1. S. Choi and J. Eastman,"Enhancing thermal conductivity of fluids with nanoparticles,"ASME International Mechanical Engineering Congress \& Exposition. San Francisco CA, vol. 66, 1995, pp. 99-105.

2. S. K. Verma, A. K. Tiwari and D. S. Chauhan, "Experimental evaluation of flat plate solar collector using nanofluids,"Energy Conversion and Management, vol. 134, 2017, pp. 103-115.

3. K. M. Pandey and R. Chaurasiya, "A review on analysis and development of solar flat plate collector,"Renewable and Sustainable Energy Reviews, vol. 67, 2017, pp. 641-650.

4. Y. Tooraj, V. Farzad, E. Shojaeizadh and S. Zinadini,"An experimental investigation on the effect of Al2O3-H2O nanofluid on the efficiency of flat-plate solar collectors,"Renewable Energy, vol. 39, 2012, pp. 293-298.

5. M. J. Muhammad, I. A. Muhammad, N. A. C. Sidik, M. N. A. W. M. Yazid, R. Mamat and G. Najafi,"The use of nanofluids for enhancing the thermal performance of stationary solar collectors: A review,"Renewable and Sustainable Energy Reviews, vol. 63, 2016, pp. 226-236.

6. S. K. Verma and A. K. Tiwari,"Application of nanoparticles in solar collectors: A Review,"Materials Today: Proceedings, vol. 2(4-5), 2015, pp. 3638-3647.

7. F. S. Javadi, R. Saidur andM. Kamalisarvestani,"Investigating performance improvement of solar collectors by using nanofluids,"Renewable and Sustainable Energy Reviews, vol. 28, 2013, pp. 232-245.

8. M. A. Sharafeldin, G. Grof andO. Mahian, "Experimental study on the performance of a flat-plate collector using WO 3 /Wate nanofluids,"Energy, vol. 141, 2017, pp. 2436-2444.

9. S. Suman, M. K. Khan and M.Pathak,"Performance enhancement of solar collectors-A review,"Renewable and Sustainable Energy Reviews. Vol. 49, 2015, pp. 192-210.

10. S. K. Verma and A. K. Tiwari, "Characterization of nanofluids as an advanced heat transporting medium for Energy Systems,"Materials Today: Proceedings, vol. 4(2), 2017, pp. 4095-4103.

11. Z. Said, R. Saidur and N. A. Rahim, "Energy and exergy analysis of a flat plate solar collector using different sizes of aluminium oxide based nanofluid,"Journal of Cleaner Production, vol. 133, 2016, pp 518-530.

12. E. Shojaeizadeh, F. Veysi and Kamandi,“A.Exergy efficiency investigation and optimization of an Al2O3-water nanofluid based Flat-plate solar collector,'Energy and Buildings, vol. 101, 2015, pp. 12-23.

13. M. A. Sharafeldin and G. Grof , "Experimental investigation of flat plate solar collector using $\mathrm{CeO} 2$-water nanofluid,"Energy Conversion and Management, vol. 155, 2018, pp. 32-41.

14. A. Kasaeian, A. T. Eshghi and M. Sameti, "A review on the applications of nanofluids in solar energy systems,"Renewable and Sustainable Energy Reviews, vol. 43, 2015, pp. 584-598.

15. A. K. Tiwari, P. Ghosh and J. Sarkar,"Solar Water Heating Using Nanofluids- A Comprehensive Overview and Environmental Impact Analysis," IJETAE, vol. 3(3), 2013, pp. 221-224.

16. W. S. Sarsam, S. N. Kazi andA. Badarudin,"A review of studies on using nanofluids in flat-plate solar collectors,"Solar Energy, vol. 122 2015, pp. 1245-1265.

17. P. K. Nagarajan, J. Sbramani and R. Sathyamurthy,"Nanofluids for Solar Collector Applications: A Review,’Energy Procedia, vol. 61, 2014, pp. 2416-2434.

18. A. Zamzamian, R. M. Keyanpour, N. Kiani, Maryam, A. Jamal, T. Milad, "An experimental study on the effect of Cu-synthesized/EG nanofluid on the efficiency of flat plate solar collectors,"Renewable Energy, vol. 71, 2014, pp. 658-664.

19. R. Dharmalingam, K. K. Sivagnanaprabhu, B. Senthil kumar, and R Thirumalai, "Nano Materials and Nanofluids: An Innovative Technology Study for New Paradigms for Technology Enhancement,"Procedia Engineering, vol. 97, 2014, pp. 1434-1441.

20. A. M. Genc, M. A. Ezan and A. Turgut, "Thermal performance of a nanofluid-based flat plate solar collector: A transient numerical study,"Applied Thermal Engineering, vol. 130, 2018, pp. 395-407.

21. H. J. Jouybari, S. Saedodin, A. Zamzamian, M. E. Nimvari and S Wongwises, "Effects of porous material and nanoparticles on the thermal performance of a flat plate solar collector: An experimental study,"Renewable Energy, vol. 114, 2017, pp. 1407-1418.

22. A. K. Sharma, A. K. Tiwariand A. R.Dixit, "Rheological behaviour of nanofluids: A review,"Renewableand Sustainable Energy Reviews, vol. 53, 2016, pp. 779-791.

\section{AUTHORS PROFILE}

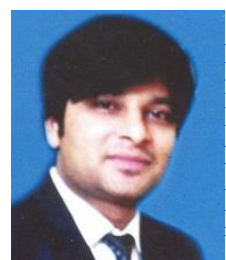

Mr. Shubham Sharma. is B. Tech Mechanical Engineering 2008 and MTech Production engineering 2011. He is presently pursuing $\mathrm{PhD}$ in department of Mechanical Engineering. He is also working as assistan professor in department of mechanical engineering Amity University Noida. He has published several papers and filed various patents. He has Worked with WIPRO Mission 10x Team for Various FDP'S and got certified from Wipro, Indian Society of technical education and Dale Carnegie organization for HIGH IMPACT TEACHING SKILLS. He is Entrepreneurship Cell Coordinator of Amity University, recognized by Department of Science and Technology, Government of India and Study abroad Program Coordinator.

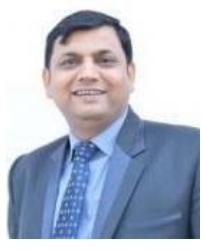

Dr. Arun Kumar Tiwari is Associate Professor and Head Mechanical Engineering Department, OIC Training \& Placement In IET Lucknow. He is Ph.D., IIT (BHU), Varanasi, MTech., IITRoorkee and B.Tech., BIET, Jhansi . He has published several research papers in Reputed journals . His Research Interests are Heat Transfer Solar Thermal Energy , Energy Storage, Nanofluids, Thermal Manufacturing , Computational Fluid Dynamics and Electronics Cooling




Particle Optimization of Ceo2/Water Nanofluids in Flat Plate Solar Collector

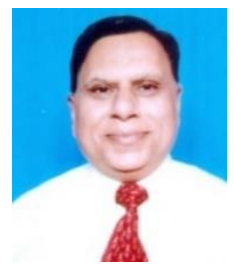

Prof. (Dr.) Ravi Prakash After obtaining B.Sc (Mechanical Engineering) Hons. degree from the Institute of Technology, Banaras Hindu University, (now IIT (BHU))proceededabroadtoobtainM.Sc. (Engineering Design)degree from the University of Salford, U.K. and Ph.D. (Materials) degreefrom Cran field niversity,U.K.ThereafterreturnedtoIndiain1975 and joined the Instituteof Technology, Banaras Hindu University as a Lecturer in Mechanical Engineering. Thereafter, waspromoted to the post of Reader in Mechanical Engineering and became full Professor in theyear1985 at an age of 34 years. Presently he is working Dean Research in Amity Institute of technology.

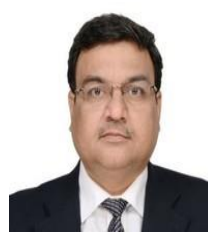

Prof.(Dr.) Sandeep Tiwari is a rare blend of academics and administration with rich and varied experience spanning over more than two decades , 19+ yrs of Teaching and 5 yrs of industry in various capacities .He is first class B.E. (Mechanical Engineering ) from Karnataka University, Dharwad and first class M.E. from University of Roorkee (Now Indian Institute Of Technology, Roorkee), Ph.D. from UP Technical University, Lucknow with Research centre Institute of Technology (BHU) Varanasi on the topic :

"Strategic Approach for Environmentally Conscious.Prof (Dr.) Sandeep Tiwari has held important positions and onerous responsibilities such as Prof. \& Head of M.E. Dept. \& then Director Research and Professor at Accurate Institute of Management and Technology Greator Noida, Professor \& Head of M.E. Dept at College of Engineering and Technology , IILM- AHL, Greator Noida , Reader in Dept of Mechanical and Automation Engineering, Amity school of Engineering , Amity University , Noida. 